\title{
Mesenteric Blood Flow Velocity and Its Relation to Circulatory Adaptation during the First Week of Life in Healthy Term Infants
}

\author{
MARIT MARTINUSSEN, ANN-MARI BRUBAKK, DAVID T. LINKER, TORSTEIN VIK, \\ AND ALICE C. YAO \\ Department of Pediatrics [M.M., A.-M.B., T.V.] and Division of Cardiology [D.T.L.], University \\ Hospital, Trondheim, Norway, and Childrens Medical Center of Brooklyn, SUNY Health \\ Science Center at Brooklyn, New York 11203 [A.C.Y.]
}

\begin{abstract}
We investigated early postnatal changes of the mesenteric circulation and its relationship to the systemic circulation in two groups of newborn infants. Group I $(n=10)$ was studied before the first feeding at $1 \mathrm{~h}$ and preprandially at 6 and $24 \mathrm{~h}$. Group II $(n=10)$ was studied before the first feeding at $2 \mathrm{~h}$ of age and preprandially and postprandially at $\mathrm{d} 3,4$, and 5 . Blood flow velocity was measured with ultrasound Doppler in the superior mesenteric artery (SMA), middle cerebral artery, subclavian artery, and aortic orifice for cardiac output (CO) calculations. Blood pressure and heart rate were monitored. SMA mean velocity (Vmean) decreased from 1 $[0.33 \pm 0.07 \mathrm{~m} / \mathrm{s}($ mean $\pm \mathrm{SD})]$ to $6 \mathrm{~h}(0.23 \pm 0.08 \mathrm{~m} / \mathrm{s}, p<$ 0.005 ) in group I, probably due to ductal steal, returning to the 1-h value at $24 \mathrm{~h}$. In contrast, middle cerebral artery Vmean remained unchanged in the first $24 \mathrm{~h}$. From d 3, SMA Vmean increased $92 \%$ postprandially, with no relation to
\end{abstract}

ABSTRACT

increasing amounts of food. The postprandial increase in SMA Vmean was not associated with changes in $\mathrm{CO}$ and blood pressure; however, a fall in relative mesenteric vascular resistance suggested regional redistribution of $\mathrm{CO}$. Middle cerebral artery Vmean increased from $\mathrm{h} 2$ to $\mathrm{d} 3$ with a further increase on $\mathrm{d} 4(p<0.01)$. This increase was associated with an increase in blood pressure. The relative fraction of $\mathrm{CO}$ to middle cerebral artery increased during the first days of life, suggesting a redistribution of blood flow to the metabolically active organs in the neonatal period. (Pediatr Res 36: 334-339, 1994)

Vmean, mean velocity

Abbreviations

BFV, blood flow velocity

EDFV, end diastolic flow velocity
During the first days of life, the intestinal circulation must adapt to feeding and to changes occurring in the postnatal transitional circulation. Ultrasound imaging and Doppler techniques permit noninvasive studies of the circulatory adaptive changes during the early period after birth. Studies on superior mesenteric artery BFV by Van Bel et al. (1) showed that superior mesenteric artery BFV increased with gestational age and body weight, whereas Leidig (2) found an increasing fasting value after introduction of feeding and a definite postprandial increase.

The objective of this study was to systematically investigate early postnatal changes of the mesenteric circulation as they relate to the overall hemodynamic adaptation in term infants. To characterize these changes, we measured the mesenteric BFV from the first hours of life through the 5 th $\mathrm{d}$. We also examined changes in cardiac

Received July 1, 1993; accepted March 17, 1994

Correspondence and reprint requests: Marit Martinussen, Department of Pediatrics, University Hospital of Trondheim, 7005 Trondheim, Norway.

Supported by The Nonwegian National Health Association. output, heart rate, blood pressure, and other regional circulations including that of a priority organ, the brain, and a secondary organ, the arm, during the first $5 \mathrm{~d}$ of life. The circulatory response to feeding was assessed from the 3 rd to the 5 th $d$ of life.

\section{METHODS}

Twenty healthy term infants were included in the study. All infants were appropriate for gestational age and were born by normal vaginal delivery after uncomplicated pregnancies. The postnatal course was uneventful and the infants were all breast fed except for two infants who were formula fed on $\mathrm{d} 3$.

Because of our concern about an excessive number of examinations for each infant within the first $24 \mathrm{~h}$, we conducted the study on two separate groups of 10 infants each. Group I (mean birth weight $3806 \mathrm{~g}$, range $2910-4580$ $\mathrm{g}$; mean gestational age $39.5 \mathrm{wk}$, range $38-41 \mathrm{wk}$ ) was studied during the first $24 \mathrm{~h}$ of life, with examinations before any feeding 20-50 min (mean $37 \mathrm{~min}$ ) after birth, 
preprandially at $6 \mathrm{~h}$, and at $24 \mathrm{~h}$ of age. Group II (mean birth weight $3665 \mathrm{~g}$, range $3020-4320 \mathrm{~g}$; mean gestational age $39.7 \mathrm{wk}$, range $39-41 \mathrm{wk}$ ) was studied at $2 \mathrm{~h}$ of age before any feed and before and after feeding on d 3, 4, and 5 .

The study was approved by the local ethical committee and written informed consent was obtained from the parents.

A duplex scanner with pulsed Doppler and color flow mapping was used (Vingmed CFM 750, Vingmed Sound, Horten, Norway). The transducer used was $7.5 \mathrm{MHz}$ for tissue imaging and $6.0 \mathrm{MHz}$ for the Doppler recordings. The maximum velocity envelope was traced immediately after each recording. The instrument software then calculated maximum and mean BFV and heart rate. The EDFV was measured manually from the hard copies of the spectral tracings. An average of at least two measurements was used for the velocity tracings and aortic diameter calculations.

Measurement of cardiac output. From a right upper parasternal long axis view, the aortic flow velocity was obtained by placing the sample volume at the level of the aortic orifice. Velocity wave forms were considered optimal when the leaflet signal was on the recordings and the characteristic sound of the aortic Doppler signal was maximal. In the parasternal long axis view, the aortic diameter was measured as the distance between the attachment of the aortic leaflets (trailing to leading edge method) in systole when the leaflets were maximally separated. By entering the diameter of the aortic orifice after the aortic velocity curve was traced, the instrument calculated stroke volume and the cardiac output was obtained by multiplying stroke volume by heart rate. The mean of at least two cardiac output calculations was used, normalized for weight, and expressed as $\mathrm{mL} / \mathrm{min} / \mathrm{kg}$.

Ductus arteriosus. Using a parasternal short axis view, the patency and direction of the ductal shunt were evaluated by color flow mapping.

$B F V$ measurements. For imaging of the superior mesenteric artery, the transducer was placed on the midabdomen above the umbilicus in the sagittal plane. Color flow mapping was used to identify the artery where it originated from the aorta. The sample volume of the pulsed Doppler was placed a few millimeters distal to the origin of the superior mesenteric artery. Angle correction was used when necessary; this varied from examination to examination. When stable wave forms were obtained, the curve was traced and the BFV was calculated.

With the guidance of color flow mapping, the middle cerebral artery was located with the transducer perpendicular to the pterion part of the temporal bone, and BFV was measured. The BFV in the right subclavian artery was recorded with the transducer in the anterior axillary line with the arm in a semiadducted position.

The examination was performed in the following order: superior mesenteric artery, cardiac output, middle cerebral artery, and finally subclavian artery. Blood pressure was then measured by an oscillometric method (SE-100, Sein Electronics, Kyung Ki-Do, Korea). Whenever rest- lessness occurred, measurements were made after the infants were properly soothed and were quiet. The total examination time was approximately $1 / 2 \mathrm{~h}$ for each infant. All infants were examined by the same investigator. None of the infants were fed before the first examination. Subsequent examinations were performed immediately before a feeding. Postprandial examinations on d 3, 4, and 5 were performed $1 / 2 \mathrm{~h}$ after the feeding had been completed.

Statistical evaluations. Analysis of variance for repeated measures was used to identify changes over time within each group, and paired $t$ test was used to identify where the changes occurred. The correlation was tested for significance with Pearson's correlation test.

\section{RESULTS}

Cardiac output. The changes in cardiac output, heart rate, and stroke volume are shown in Figure 1. In group

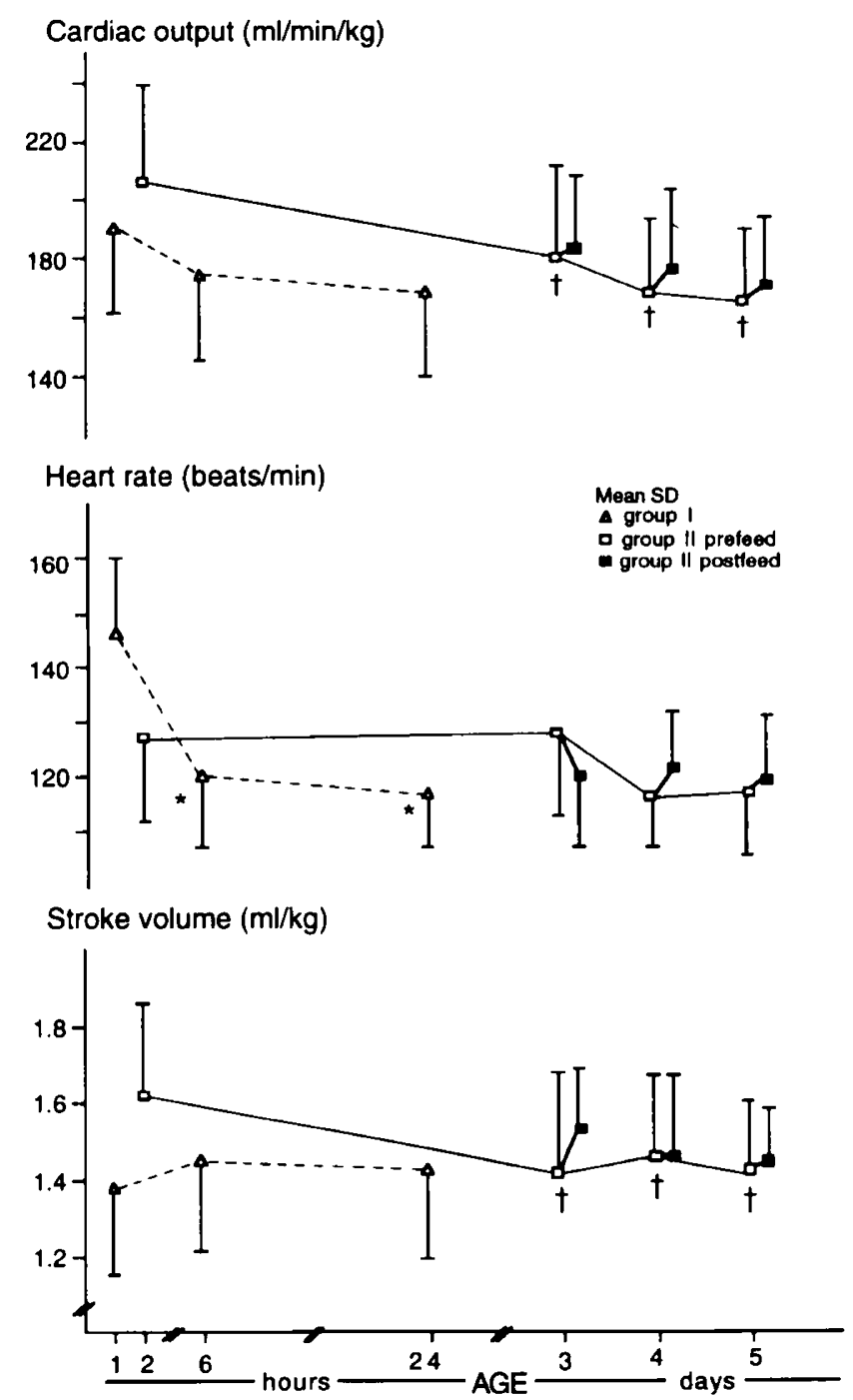

Figure 1. Cardiac output, heart rate, and stroke volume changes in two groups of term infants. Group $1(n=10)$ was examined before any feeding at $1 \mathrm{~h}$ and preprandially at 6 and $24 \mathrm{~h}$. Group $2(n=10)$ was examined before any feeding at $2 \mathrm{~h}$ and pre- and postprandially on $\mathrm{d} 3$, 4 , and $5 .{ }^{*}, p<0.0001$ is $1 \mathrm{~h} ; \dagger, p<0.05$ is $2 \mathrm{~h}$. 
I, there was no change in cardiac output. Heart rate decreased significantly from 1 to $6 \mathrm{~h}$. However, the increase in stroke volume was not significant. In group II, cardiac output decreased from h 2 to $d 3$ with no further change. There was no change in heart rate, but stroke volume decreased significantly from $h 2$ to $d 3$ and was maintained through $\mathrm{d} 5$. There were no postprandial changes in cardiac output, heart rate, and stroke volume.

Ductus arteriosus. In group I, at $6 \mathrm{~h}$ of age, all infants had an open ductus arteriosus with left-to-right shunt. By $24 \mathrm{~h}$ there was still left-to-right shunting in five infants, but the ductus was closed in the other five. In group II, at $2 \mathrm{~h}$ of age, all infants also had an open ductus arteriosus with left-to-right shunt. The ductus was closed in all infants on $\mathrm{d} 3$.

Blood pressure. The changes in blood pressure are shown in Figure 2. In group I, neither mean nor diastolic blood pressure changed during h 1, 6, and 24 . In group II, mean and diastolic blood pressure increased from $\mathrm{h} 2$ to d 3 , and was sustained at the same level through $\mathrm{d} 5$. There were no postprandial changes.

Superior mesenteric artery. Superior mesenteric artery BFV results are shown in Figure 3. In group I, superior mesenteric artery Vmean decreased from 1 to $6 \mathrm{~h}$, returning to the $1-\mathrm{h}$ value at $24 \mathrm{~h}$. Superior mesenteric artery EDFV started out rather low $(0.05 \pm 0.08 \mathrm{~m} / \mathrm{s}$, mean \pm $\mathrm{SD})$ and increased until $24 \mathrm{~h}(0.14 \pm 0.04 \mathrm{~m} / \mathrm{s}$, mean \pm
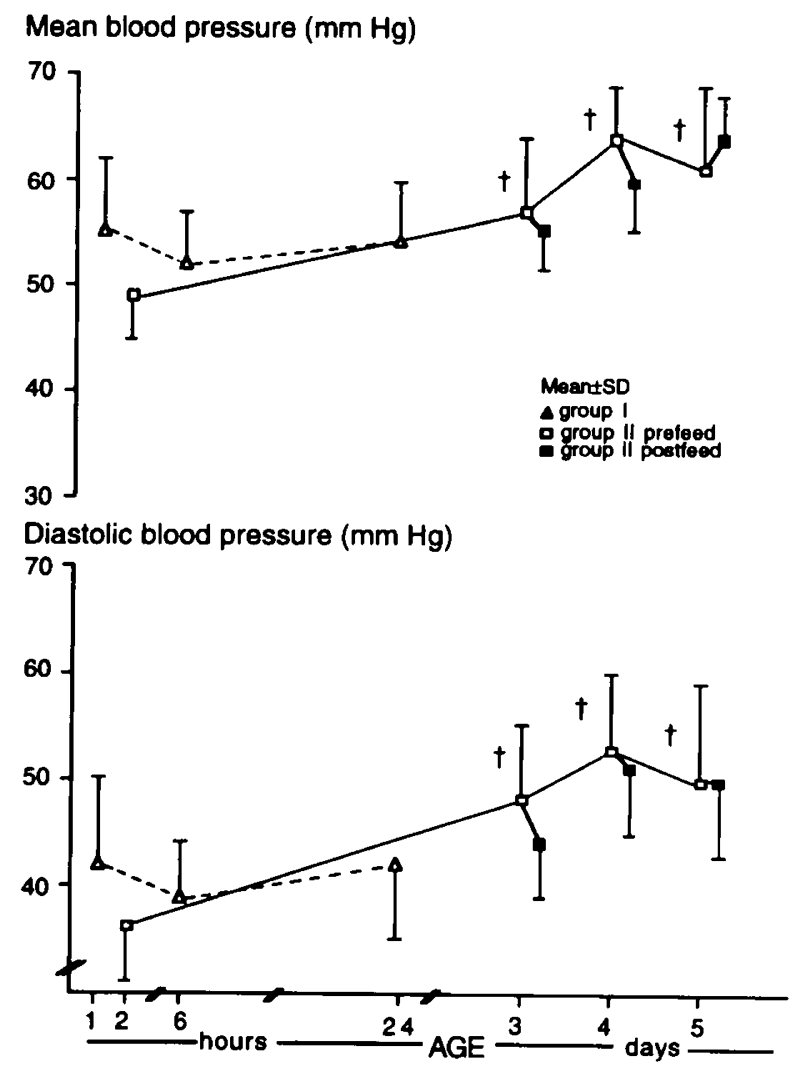

Figure 2. Blood pressure changes in two groups of term infants. Group $1(n=10)$ was examined before any feeding at $1 \mathrm{~h}$ and preprandially at 6 and $24 \mathrm{~h}$. Group $2(n=10)$ was examined before any feeding at $2 \mathrm{~h}$ and pre- and postprandially on $\mathrm{d} 3,4$, and $5 .+, p<0.01$ vs $2 \mathrm{~h}$.
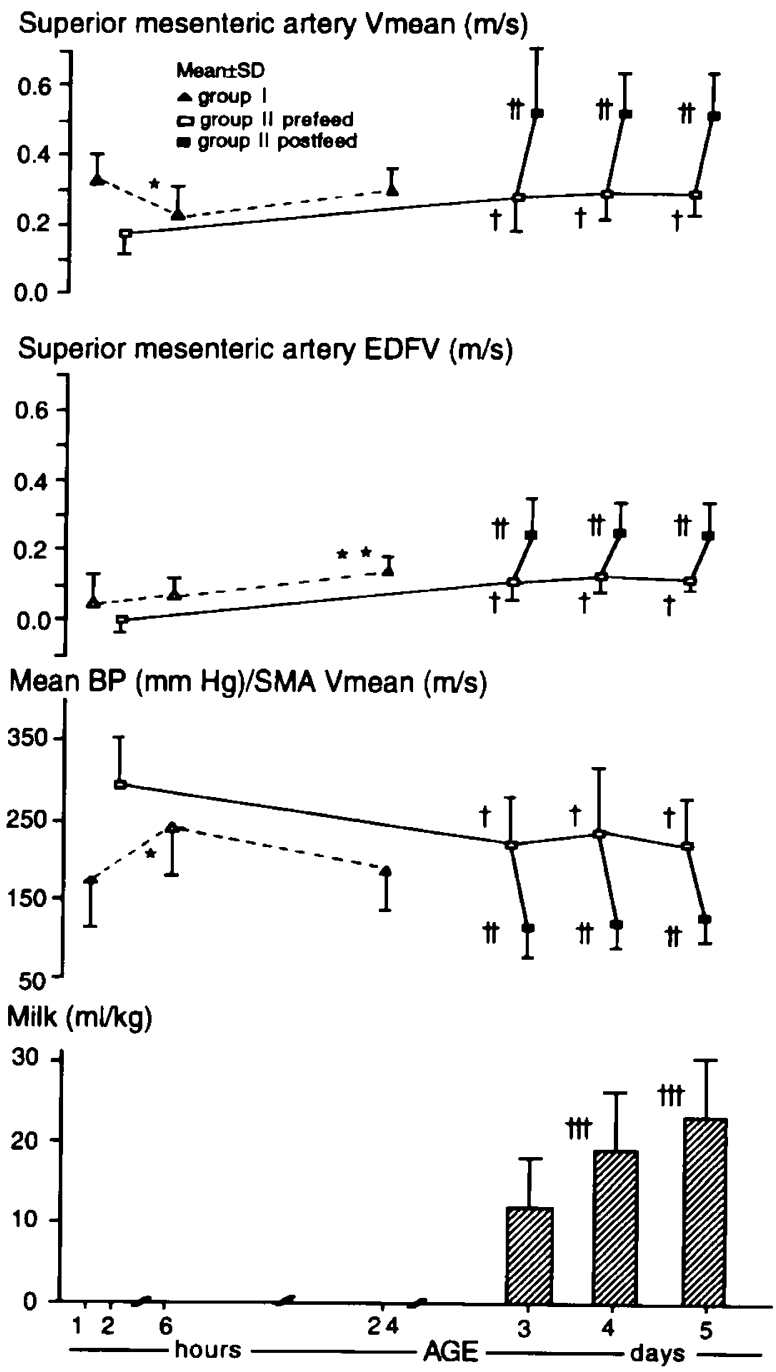

Figure 3. Changes in superior mesenteric artery (SMA) Vmean, EDFV, and index of relative vascular resistance [mean blood pressure $(B P) / S M A$ Vmean] in two groups of term infants. Group $1(n=10)$ was examined before any feeding at $1 \mathrm{~h}$ and preprandially at 6 and $24 \mathrm{~h}$. Group $2(n=10)$ was examined before any feeding at $2 \mathrm{~h}$ and preprandially and postprandially on $\mathrm{d} 3,4$, and 5 . Bars indicate increasing amounts of milk feed on $\mathrm{d} 3$ through $5 .{ }^{*}, p<0.01 v s 1$ and $24 \mathrm{~h} ;{ }^{* *}, p$ $<0.001$ vs $1 \mathrm{~h} ; \dagger, p<0.01$ vs $2 \mathrm{~h} ; \ddagger, p<0.005$ vs prefeeding; $\dagger+\dagger, p<$ 0.01 vs d 3 .

SD). At $1 \mathrm{~h}$ of age, two infants had negative and eight positive EDFV. At 6 and $24 \mathrm{~h}$, EDFV was positive in all infants. The ratio mean blood pressure:superior mesenteric artery Vmean was used as an index of relative mesenteric vascular resistance. This ratio increased from 1 to $6 \mathrm{~h}$, and decreased from 6 to $24 \mathrm{~h}$. In group II, the prefeeding superior mesenteric artery Vmean and EDFV increased from $h 2$ to $d 3$ with no further change. At $2 \mathrm{~h}$ of age, one infant had negative and seven had zero EDFV. From d 3 onward, all measurements of EDFV were positive. The preprandial relative vascular resistance decreased from $\mathrm{h} 2$ to $\mathrm{d} 3$ and was maintained thereafter. Postprandially there was a significant increase in both superior mesenteric artery Vmean (85-92\%) and EDFV (103-145\%). The relative vascular resistance de- 
creased postprandially, suggesting a fall in mesenteric vascular resistance. There was no change in the magnitude of the postprandial response, although the amount of food ingested increased significantly from $d 3$ to $d 4$. No correlation was found $(r=0.26, p=0.12)$ between the amount of milk ingested and the postprandial response.

Middle cerebral artery. The BFV changes in the middle cerebral artery are shown in Figure 4. In group I, there was no change in middle cerebral artery Vmean during $h$ 1,6 , and 24 . Middle cerebral artery EDFV was positive in all infants at $1 \mathrm{~h}$ of age and increased at $24 \mathrm{~h}$. During the first $24 \mathrm{~h}$, there was no correlation between Vmean and mean blood pressure $(r=0.14)$. In group II, middle cerebral artery Vmean increased from $\mathrm{h} 2$ to $\mathrm{d} 3$ with a further increase from $\mathrm{d} 3$ to $\mathrm{d} 4$ and remained unchanged on d 5. Middle cerebral artery EDFV was zero at $2 \mathrm{~h}$ of age in one infant and positive in the others. EDFV increased by $d 3$, with a further increase on $d 4$. In group II, there was a significant correlation between Vmean and mean blood pressure $(r=0.53, p<0.0001)$.

Fraction of cardiac output. The ratio of BFV to cardiac output was used as an estimate of the fraction of cardiac output to the various regional vascular beds (Fig. 5). In group I, the relative fraction to the superior mesenteric artery increased from 6 to $24 \mathrm{~h}$, whereas the relative fraction to the middle cerebral artery increased from 1 to 6 h. In group II, the relative fraction to the superior mesenteric artery and middle cerebral artery increased from $\mathrm{h} 2$ to $\mathrm{d} 3$. The middle cerebral artery fraction increased fur-

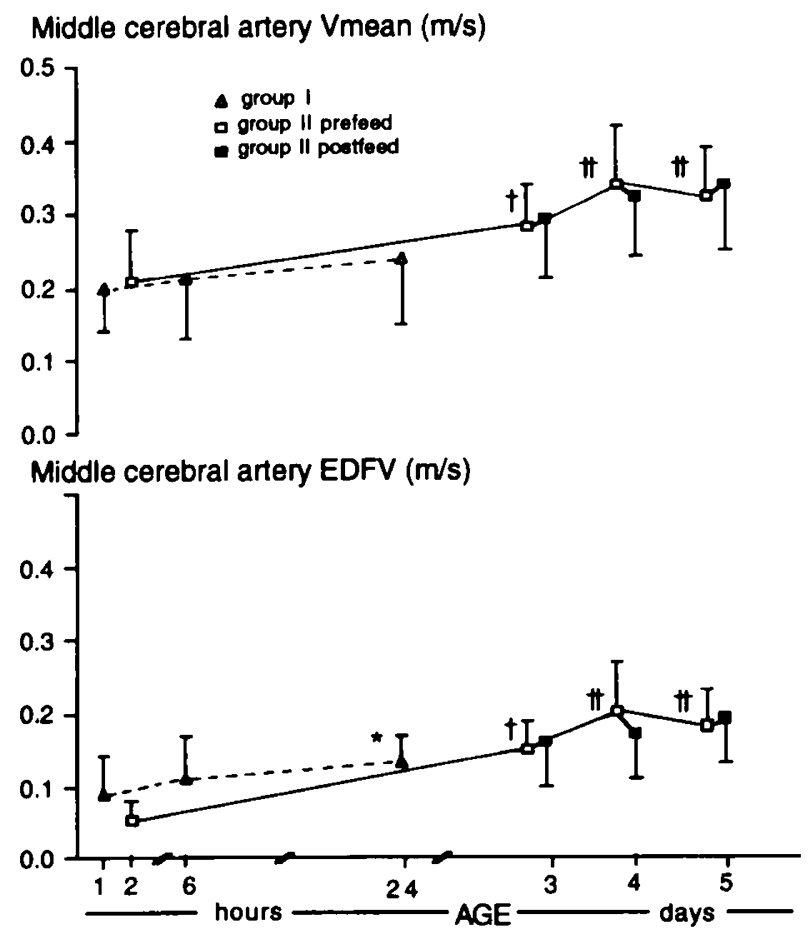

Figure 4. Changes in middle cerebral artery Vmean and EDFV in two groups of term infants. Group $1(n=10)$ was examined before any feeding at $1 \mathrm{~h}$ and preprandially at 6 and $24 \mathrm{~h}$. Group $2(n=10)$ was examined before any feeding at $2 \mathrm{~h}$ and preprandially and postprandially on $\mathrm{d} 3,4$, and $5 .{ }^{*}, p<0.01$ vs $1 \mathrm{~h} ; \dagger, p<0.005$ vs $2 \mathrm{~h} ; \ddagger, p<0.01$ vs d 3 .
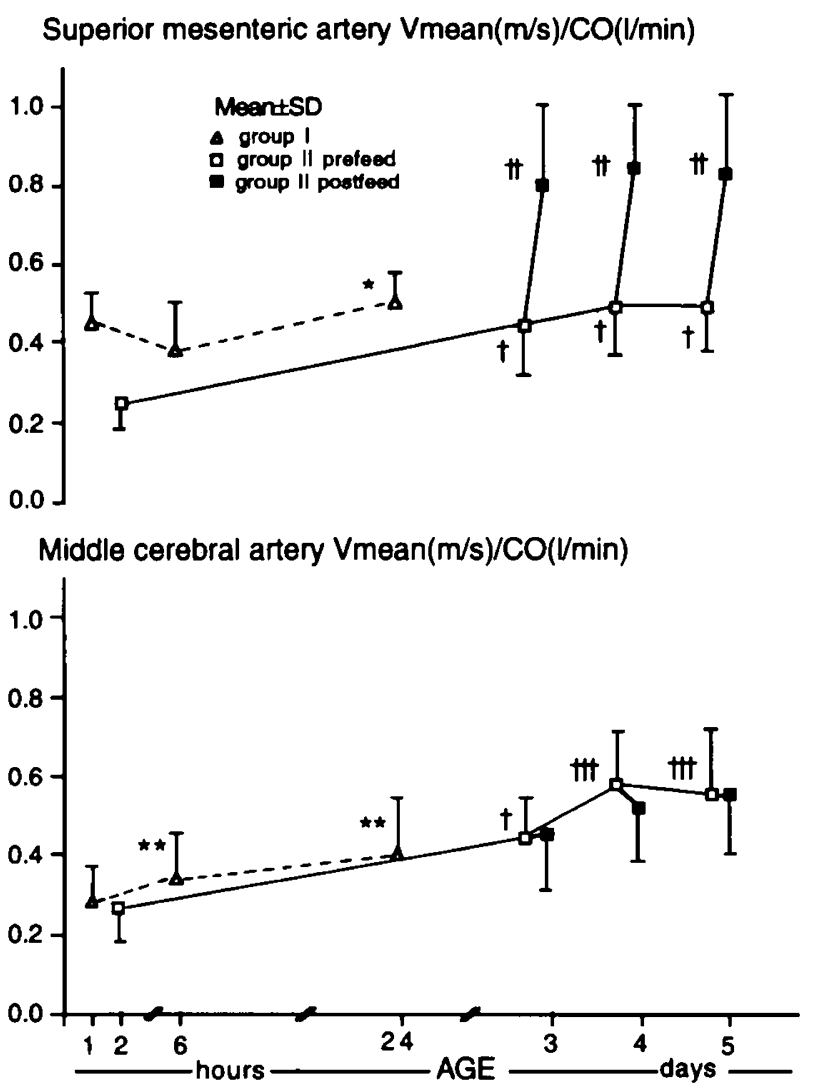

Figure 5. The ratio of superior mesenteric and middle cerebral artery Vmean to cardiac output $(\mathrm{CO})$ in two groups of term infants. Group $1(n$ $=10$ ) was examined before any feeding at $1 \mathrm{~h}$ and preprandially at 6 and $24 \mathrm{~h}$. Group $2(n=10)$ was examined before any feeding at $2 \mathrm{~h}$ and preprandially and postprandially on $\mathrm{d} 3,4$, and $5 .^{*}, p<0.01 v s 6 \mathrm{~h}$; ${ }^{* *}$, $p<0.01$ vs $1 \mathrm{~h} ; \dagger, p<0.001$ vs $2 \mathrm{~h} ; \ddagger, p<0.0001$ vs prefeeding; $p<0.0001 v s \mathrm{~d} 3$.

ther on $\mathrm{d} 4$. Feeding increased the fraction to the superior mesenteric artery significantly; however, it did not influence the fraction to the middle cerebral artery.

Subclavian artery. Vmean and the relative fraction to the subclavian artery did not change during the course of the study in any of the two groups, nor were there any postprandial changes (data not shown).

\section{DISCUSSION}

Systemic circulation. The early postnatal changes in the systemic circulation may be explained both by left to right ductal shunting and by the decreasing effect from the catecholamine surge at birth. The fall in heart rate from 1 to $6 \mathrm{~h}$ of age may reflect the waning effect of the catecholamine surge at birth (3). The increase in mean and diastolic blood pressure and the decrease in cardiac output and stroke volume from $2 \mathrm{~h}$ to $\mathrm{d} 3$ probably reflects ductal closure (4-8).

Superior mesenteric artery. The low superior mesenteric artery $\mathrm{Vmean}$ at $6 \mathrm{~h}$ of age in group $\mathrm{I}$ and at $2 \mathrm{~h}$ of age in group II were, to a large extent, a result of very low, zero, or even negative EDFV. This was most probably due to the left-to-right shunt through the ductus arteriosus, resulting in ductal steal (9). The peak in the relative 
vascular resistance during the first hours of life suggests that intestinal vasoconstriction plays a role in the regulation of the systemic circulation in the presence of a ductal shunt. The mesenteric blood flow thus may be compromised if the ductal shunt were to increase to a clinically symptomatic level. The increase in preprandial superior mesenteric artery Vmean and decrease in relative vascular resistance from $2 \mathrm{~h}$ onward may largely be explained by the closure of the ductus arteriosus, although a priming effect of feeding may also have contributed $(2,10,11)$. Once the feeding was regularized on $d 3$, we found a significant postprandial increase in superior mesenteric artery BFV; however, the magnitude of the postprandial change was not correlated with the increasing amount of milk taken from d 3 to 5 . Others have reported that even small amounts of food can result in a significant increase in superior mesenteric artery BFV (12). The observed postprandial increase in intestinal BFV was probably accomplished by intestinal vasodilation, as indicated by the decrease in relative mesenteric vascular resistance.

Middle cerebral artery. Ductal steal has also been reported to decrease brain blood flow $(13,14)$. However, in our study, middle cerebral artery Vmean results suggest that the brain blood flow is unaffected by ductal steal. Similar results have been reported from studies of the internal carotid artery (15). The lack of correlation between blood pressure and Vmean during the first $24 \mathrm{~h}$ in the presence of ductal shunting suggests that newborn infants can autoregulate their brain blood flow. Middle cerebral artery Vmean as well as blood pressure increased with age in group II. The correlation between middle cerebral artery Vmean and blood pressure in group II suggests a pressure-passive relationship. However, studies in newborn animals and humans have shown that healthy newborns can autoregulate their brain blood flow, but within a more narrow range than adults $(16,17)$. Ramaekers et al. (18) found that the upper limit for autoregulation increased as a function of age in older infants. A more likely explanation for the simultaneous increase in blood pressure and brain BFV may therefore be a shift of the autoregulation range in the first week of life. The increase in middle cerebral artery BFV may also be a reflection of increasing metabolic demand (19-21). We cannot, however, exclude the possibility that the increase in middle cerebral artery Vmean is influenced by changes in vessel size as a result of increasing blood pressure (22).

Subclavian artery. The aim of measuring the subclavian artery BFV was to study limb perfusion in relation to feeding. In contrast to the present results, a transient decrease in limb blood flow measured by venous occlusion plethysmography has been shown to occur after feeding in term infants $(23,24)$. Because the measurement in the subclavian artery was the last measurement in our study, we may have missed this short-lived hypoperfusion phase. Because the subclavian artery also supplies neck and intrathoracic structures, changes in upper limb blood flow during feeding may be masked. The vessel may therefore be unsuitable for measurement of arm blood flow during feeding. The effect of muscular activity in the few infants who were restless may have contributed to the lack of change after feeding.

Cardiac output distribution. During the first $5 \mathrm{~d}$ of life, the fraction of cardiac output to the brain increased. Others reported decreased skin and limb blood flow (25, 26) during the first week of life in healthy term infants. We speculate that during the first week of life the newborn infant redistributes his or her cardiac output with increased perfusion to metabolically active organs such as the brain. With feeding, the postprandial increase in the relative fraction of cardiac output to the gut, but not to the brain, suggests redistribution of cardiac output that did not influence brain blood flow.

In conclusion, we found significant changes in the systemic and regional circulation during the first hours of life in healthy term infants. These changes may be explained by the catecholamine surge at birth and ductal steal. The intestinal circulation was affected by ductal steal, in contrast to the cerebral circulation, which was relatively spared. The simultaneous increase in middle cerebral artery BFV and blood pressure may suggest changing autoregulation during the first week of life. The increasing BFV to the brain may also be explained by increasing metabolic demands. On d 3 of life, the circulatory responses to feeding were well established. This study of the early postnatal circulatory adaptation and the circulatory responses to feeding in the healthy term infant will serve as a reference study in preterm, smallfor-gestational-age, and sick newborn infants.

Acknowledgment. The authors thank Matt Avitable, Scientific Academic Computing Center SUNY HSCB NY, for his statistical assistance.

\section{REFERENCES}

1. Van Bel F, Van Zwieten PHT, Guit GL, Schipper J 1990 Superior mesenteric artery blood flow velocity and estimated volume fow: duplex Doppler US study of preterm and term neonates. Radiology 174:165-169

2. Leidig E 1989 Pulsed Doppler ultrasound blood fow measurements in the superior mesenteric artery of the newborn. Pediatr Radiol 19:169-172

3. Hägnevik K, Faxelius G, Irestedt H, Lagercrantz H, Lundell B, Persson B 1984 Catecholamine surge and metabolic adaptation in the newborn after vaginal delivery and caesarean section. Acta Paediatr Scand 73:602-609

4. Emmanouilides GC, Moss AJ, Duffie ER, Adams FH 1964 Pulmonary arterial pressure changes in human newborn infants from birth to 3 days of age. J Pediatr 65:327-333

5. Gessner I, Krovetz LJ, Benson RW, Prystowsky H, Stenger V, Eitzman DV 1965 Hemodynamic adaptations in the newborn infant. Pediatrics 36:752-762

6. Hirsimäki H, Kero P, Wanne O, Erkkola R, Makoi Z 1988 Doppler-derived cardiac output in healthy newborn infants in relation to physiological patency of the ductus arteriosus. Pediatr Cardiol 9:79-83

7. Burnard ED, Grauaug A, Gray RE 1966 Cardiac output in the newborn infant Clin Sci 31:121-133

8. Winberg P, Jansson M, Marions L, Lundell BPW 1989 Left ventricular output during postnatal circulatory adaptation in healthy infants born at full term. Arch Dis Child 64:1374-1378

9. Meyers RL, Alpan G, Lin E, Clyman RI 1991 Patent ductus arteriosus, Indomethacin, and intestinal distension: effects on intestinal blood flow and oxygen consumption. Pediatr Res 29:569-574

10. Coombs RC, Morgan MEI, Durbin GM, Booth IW, McNeish AS 199) Gut blood flow velocities in the newborn: effects of patent ductus arteriosus and parenteral indomethacin. Arch Dis Child 65:1067-1071

11. Norris CP, Barnes GE, Smith E, Granger J 1979 Autoregulation of superior mesenteric flow in fasted and fed dogs. Am J Physiol 237:H174-H177 
12. Gladman G, Sims DG, Chiswich ML 1991 Gastrointestinal blood flow velocity after the first feed. Arch Dis Child 66:17-20

13. Ando Y, Takashima S, Takeshita K 1983 Postnatal changes of cerebral blood flow velocity in normal term neonates. Brain Dev 5:525-528

14. Archer LNJ, Evans DH, Levene MI 1985 Doppler ultrasound examination of the anterior cerebral arteries of normal newborn infants: the effect of postnatal age. Early Hum Dev 10:255-260

15. Sonesson S-E, Winberg P, Lundell BPW 1987 Early postnatal changes in intracranial blood flow velocities in term infants. Pediatr Res 22:461464

16. Hernandez MJ, Brennan RW, Bowman GS 1980 Autoregulation of cerebral blood flow in the newborn dog. Brain Res 184:199-202

17. van de Bor M. Walther FJ, Sims ME 1990 Acceleration time in cerebral arteries of preterm and term infants. J Clin Ultrasound 18:167-171

18. Ramaekers VT, Casaer P, Daniels H, Marchal G 1990 Upper limits of brain blood flow autoregulation in stable infants of various conceptional age. Early Hum Dev 24:249-258

19. Scopes JW 1966 Metabolic rate and temperature control in the human baby. Br Med Bull 22:88-91

20. Abrams RM, Ito M, Frisinger JE, Patlak CS, Pettigrew KD, Kennedy C 1984
Local cerebral glucose utilization in fetal and neonatal sheep. Am J Physiol 246:R608-R618

21. Rosenberg AR, Jones DM, Traystman RJ, Simmons MA, Molteni RA 1982 Response of cerebral blood flow changes in $\mathrm{pCO}_{2}$ in fetal, newborn, and adult sheep. Am J Physiol 242:H862-H866

22. Paulson O B, Strandgaard S Edvinsson 1990) Cerebral autoregulation. Cerebrovasc Brain Metab Rev 2:161-192

23. Yao AC, Wallgren GC, Sinha NS, Lind J 1971 Peripheral circulatory response to feeding in the newborn infant. Pediatrics 47:2:378-383

24. Yao AC, Valencia G, Frankfurt P 1988 Upper versus lower limb blood flow in response to feeding in growing preterm infants. In: Jones CT (ed) Researches in Perinatal Medicine (VII), Fetal and Neonatal Development. Perinatology Press, Ithaca, NY, pp 640-644

25. Suichies HE, Brouwer C, Aarnoudse JG, Jentink HW, de Mul FFM, Greve J 199) Skin blood flow changes, measured by laser Doppler flowmetry, in the first week after birth. Early Hum Dev 23:1-8

26. Wu PYK, Wong WH, Guerra G, Mirande R, Godoy RR, Preston B, Schoe ntgen S, Levan NE 1980 Peripheral blood flow in the neonate. 1. Changes in total, skin and muscle blood flow with gestational and postnatal age. Pediatr Res 14:1374-1378

\section{ANNOUNCEMENT Search for European Chief Editor \\ Pediatric Research}

After five years of service, the European Editorial Board of Pediatric Research will complete its term on December 31, 1995. The Board of Trustees of the International Pediatric Research Foundation has established a Search Committee to review the credentials of qualified candidates for a new European Chief Editor and to make recommendations to the Board, which has the responsibility for final selection.

The Search Committee seeks candidates or recommendations for individuals who might serve as European Chief Editor. The European Chief Editor must be a member of the European Society for Pediatric Research. Interested individuals should submit six copies of their curriculum vitae and those of at least four individuals in their locale to serve as Associate Editors. In addition, the application should include suggestions for further improving the quality of Pediatric Research and its growth as a unique biomedical publication. The office carries a budget for supporting staff and an honorarium. Additional information regarding the operation of the European Office can be obtained from the current European Editor, Pieter J. J. Sauer, M.D., Sophia Children's Hospital, Dr. Molewaterplein 60, 3015 GJ Rotterdam, The Netherlands.

The Search Committee will interview selected candidates immediately before the annual meeting of the Board of Trustees in September 1995. Applications should be sent before February 1, 1995 to: Gunnar Sedin, M.D., Chairman, Search Committee, Department of Pediatrics, Uppsala University Children's Hospital, S-751 85 Uppsala, Sweden. 